\title{
一般化包絡分析法と遺伝アルゴリズムによる多目的 最適化の一手法*
}

\author{
尹 禮分 $\dagger$. 中山 弘隆
}

\section{A Multi-Objective Optimization Method Combining \\ Generalized Data Envelopment Analysis and \\ Genetic Algorithms*}

Yeboon YUN ${ }^{\dagger}$, Hirotaka NAKAYAMA ${ }^{\ddagger}$, Tetsuzo TANINO ${ }^{\dagger}$ and Masao ARAKAWA ${ }^{\S}$

\begin{abstract}
In this paper, a method using generalized data envelopment analysis and genetic algorithms is proposed for finding efficient frontiers in multi-objective optimization problems. The proposed method can yield desirable efficient frontiers even in nonconvex cases. It will be proved that the proposed method overcomes shortcomings of existing methods through several numerical examples.
\end{abstract}

\section{1. はじめに}

多目的最適化問題は一般に次のように定式化される.

$$
\begin{array}{ll}
\min _{\boldsymbol{x}} & \boldsymbol{f}(\boldsymbol{x})=\left(f_{1}(\boldsymbol{x}), \cdots, f_{m}(\boldsymbol{x})\right)^{\mathrm{T}} \\
\text { s.t. } & \boldsymbol{x} \in X=\left\{\boldsymbol{x} \mid g_{j}(\boldsymbol{x}) \leq 0, j=1, \cdots, l\right\}
\end{array}
$$

ただし， $\boldsymbol{x}=\left(x_{1}, \cdots, x_{n}\right)^{\mathrm{T}}$ とする. しかし, 多目的最適化 問題ではすべての目的関数 $f_{i}(\boldsymbol{x})(i=1, \cdots, m)$ を同時に 最適化する解が必ずしも存在せず, そのため, ‘パレート 最適解 (Pareto optimal solution)' という概念が導入さ れる $[10]$. パレート最適解は効率解 (efficient solution) とも呼ばれる。また，パレート最適解に対する目的関数 の值をパレート最適值と呼ぶ. 多目的最適化問題におい てパレート最適解がまず意思決定解の候補となる [8]. パ レート最適解は通常, 複数個あり, 意思決定者はその中 から一つの解を選び出すことになる. そのため, 従来, 意 思決定者との対話によって最終的な意思決定解を求める という対話型多目的計画の手法がいくつか提案されてい

\footnotetext{
*原稿受付 1999 年 5 月 27 日

†阪大学 大学院 工学研究科 Graduate School of Engineering, Osaka University ; 2-1 Yamada-oka, Suita city, Osaka 565-0871, JAPAN

‡甲南大学理学部 Faculty of Science, Konan University; 8-9-1 Okamoto, Higashinada, Kobe city, Hyogo 6588501, JAPAN

$\S$ 香川大学 工学部 Faculty of Engineering, Kagawa University;1-1 Saiwaicho, Takamatsu city, Kagawa 760-8526, JAPAN

Key Words: generalized data envelopment analysis, genetic algorithms, multi-objective optimization, Pareto optimal solutions.
}

る $[10]$. ところで, 実際の工学設計の問題では種々の評 価関数の形が陽にはわからず, 構造解析, 熱解析, 流体 解析等の解析によってはじめて設計変数の各值に対する 評価関数值がわかることが多い.一般にこのような解析 には多大の時間がかかり，対話型多目的計画の手法を適 用することは困難となる。しかし，2，3-目的関数の最適 化問題のときには，目的空間におけるパレート最適値の 集合，すなわち，効率フロンティアを提示することによ り，意思決定がやりやすくなる．

これまで, 効率フロンティアを求めるための手法とし ては種々考案されているが, 本論文では目的関数值が解 析によってはじめて定められ，微分情報を用いるのが困 難な場合を想定するため, 遺伝アルゴリズム (Genetic Algorithms，GA) を用いる方法について考察する。さ て，GA を用いる方法において, 各世代での個体群の中 でパレート最適な個体をパレート個体と呼ぶことにする. 効率フロンティアを求めるために GA を用いる方法とし て有名なものにランキング法がある。しかし, ランキン グ法 $[5,6]$ では滑らかな効率フロンティアを得ることが困 難であり，また，並列選択とパレート保存戦略にもとづ くGAによる方法 [12] (以下では玉置ほがの方法と呼ぶ) では，途中の世代において得られたパレート個体の中で， 最終的なパレート個体にならないものが多く存在するこ とがある。

一方，荒川らによって包絡分析法 (Data Envelopment Analysis, DEA) と GA を併用する方法も提案されてい る [1]. DEA は, 多入力-多出力の生産システムにおい 
て, 意思決定体 (Decision Making Unit, DMU) の相対 的効率性を測定するために, Charnes-Cooper-Rhodes によって提案された [3]. これまで, DEAに対して数多く のモデルが提案されてきたが, その中でも代表的なモデ ルとしては, 生産可能集合をどのように定めるかによっ て, CCR モデル [3], BCC モデル [2], FDH モデル [13] 等がある. CCR モデルは与えられたデータ集合の凸錐, BCC モデルは与えられたデー夕集合の凸包, FDH モデ ルはFDH (Free Disposable Hull[4]) が，それぞれの生 産可能集合になっている．荒川らによる方法では, DEA として CCR モデル，もしくは BCC モデルを用いて各世 代における非パレート個体を効率よく淘汰している。し かし，CCR モデルやBCC モデルは目的空間における実 行可能集合の凸包を考察の対象とするため, 効率フロン ティアが凸になる問題にしか適用できない.

そこで, 本論文では一般化 DEA (Generalized DEA, GDEA)[14] を GA と併用する方法を提案する. GDEA は, CCR モデル, BCC モデル, FDH モデルを含む一 般的な DEA モデルで，ランキング法と荒川らの方法 [1] の長所を受け継ぎながら, かつ非凸な効率フロンティア をも求めることができる.さらに，いくつかの例題を通 して途中の世代で生成されたパレート個体のほとんどが 最終的なパレート個体になり, 少ない世代数で良い近似 の効率フロンティアが得られることを示す.

\section{GA による多目的最適化}

GA の適用によって, より良い近似の効率フロンティ アを得るためには, 通常, 世代数を多くとることが必要 である，このとき，比較的早い世代で個体群が多様性を 失ってしまう現象 (初期収束と呼ばれる) が生じることが しばしばある。このような現象を回避するために, シェ アリングの方法 [5-7], TDGA[9]による方法などが提案 されている.

本研究の目的は少ない世代数で効率フロンティアの良 い近似を与えることであり, そのために以下に GDEA と GA による方法を提案する。個体群に多様性をもたせる 必要が出てきたときには, シェアリングや TDGA 法な どの工夫を取り入れればよい.

まず, 多目的最適化 GA の手法の中から比較対象の手 法として, Fonseca らのランキング法 [5], 玉置ほかの方 法 [12], DEA による方法 [1] を取り扱うので, 本章では この手法についての説明を述べる.

Fonseca らのランキング法 [5] では，ある個体が $n$ 個の 個体に優越されているとき, その個体のランクは $(1+n)$ と定められる. そのとき, ランクが 1 であれば, 次世代 まで生き残すという方法である.ランキング法として一 般的になっているもう一つの手法である Goldberg のラ
ンキング法 [6] ではランク 1 のものは Fonseca らのラン キング法と同様である。次にランク 1 の個体を除いた集 団に同様な手法でランクを求め, ランク 2 を決定する. この手法では, Fig. 1 (b) の個体 $E, F$ にあるように真の フロンティアから本来遠いはずの個体 $F$ の方が高いラン クを得ることはなくなる. また, 個体 $G$ のようにかなり 効率フロンティアに近いものも, 個体 $E$ のようにかなり 遠いものも同一のランクになってしまうように定量的な 評価とは必ずしも言い難いものであった. ランキング法 は, 各世代でのパレート個体が必ずしも最終的なパレー 卜個体になるとは限らず非パレート個体が長く生き残さ れることがあり，一般に効率フロンティアを求めるのに 多くの世代まで計算することが必要である.

一方, 玉置ら [12] は, 各目的関数について独立に選択 を行う並列選択法およびパレート個体を次世代まで残す パレート保存戦略を組み合わせた方法を提案した。この 方法によって, 広範な多目的最適化問題に対し効率フロ ンティアを効率よく求めることができる。しかし, 各世 代で求められたパレート個体の中には, 正しい効率フロ ンティアから離れたものが多く存在することがある.

上記で述べた方法の問題点を解消するために, DEA に よる方法 [1] が荒川らによって提案された。この方法で

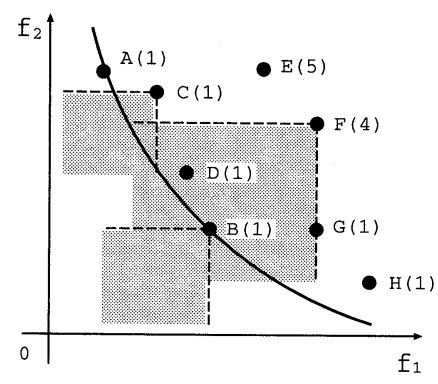

(a) Fonseca et al.

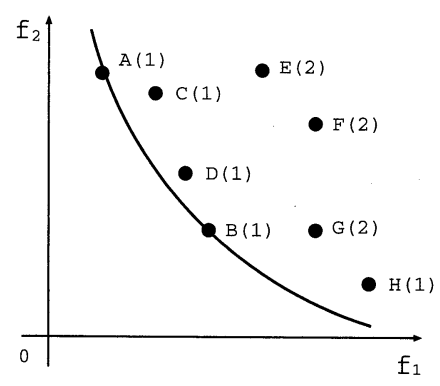

(b) Goldberg

Fig. 1 Ranking method: The number in brackets indicates rank of each population at a generation, and the curved line indicates the efficient frontier. 
は, 個体 $\boldsymbol{x}^{o}(o=1, \cdots, p)$ の効率度 $\theta$ が次の線形計画問題 を解くことによって求められる.

$$
\begin{array}{ll}
\min _{\theta, \boldsymbol{\lambda}} & \theta \\
\text { s.t. } & {\left[\boldsymbol{f}\left(\boldsymbol{x}^{1}\right), \cdots, \boldsymbol{f}\left(\boldsymbol{x}^{p}\right)\right] \boldsymbol{\lambda}-\theta \boldsymbol{f}\left(\boldsymbol{x}^{o}\right) \leq 0,} \\
& \boldsymbol{\lambda} \geq 0, \quad \boldsymbol{\lambda} \in \mathbf{R}^{p}
\end{array}
$$

効率度 $\theta$ は, DEA 効率フロンティア1 からどれだけ離 れているかを示すもので, $(0,1]$ の值をとり, $\theta$ が 1 の とき, CCR 効率的であるというが, 個体 $\boldsymbol{x}^{\circ}$ は DEA 効 率フロンティア上にあることを示す. GA における評価 は，この効率度をそのまま適応度として行われる. DEA による方法は, Fig. 2 に示すように個体群の目的関数值 に対する凸包を考え，その集合上での優越関係を調べる ため, 効率フロンティアから遠く離れている個体 $E, F$ が早く淘汰され, より早く効率フロンティアを求めるこ とができる。このように効率フロンティアが凸な場合 ${ }^{2}$, 最終的には非パレート個体となる個体を早い段階で淘汰 することができる。しかしながら，効率フロンティアが 凸でなければ, DEA による方法では効率フロンティアの くぼんだ部分を求めることはできない.

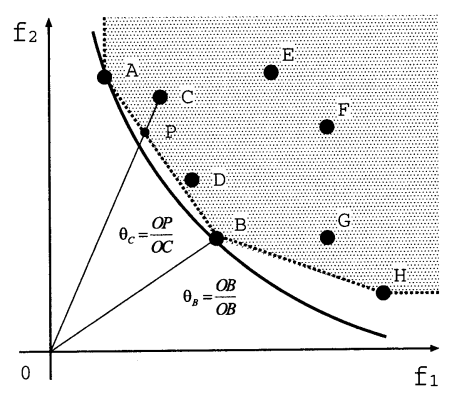

Fig. 2 GA with DEA method: The curved line indicates the efficient frontier, and the dotted line represents the DEA efficient frontier.

\section{GDEA と GA による多目的最適化}

CCR モデルや BCC モデルが, 与えられたデー夕集 合の凸包にもとづいて効率度を算出するのに対し, FDH モデルでは Free Disposable Hull にもとづいて効率度を 算出するため, 非凸な DEA 効率フロンティアが得られ る、筆者らによって提案された GDEA[14] は, 一つのパ ラメータを変化させることによりこれら既存の DEA モ

\footnotetext{
1本論文では, CCR モデル等の DEA モデルによって, 生成さ れる効率フロンティアを DEA 効率フロンティアとよぶ.

2効率フロンティアの集合を $E\left(\subset \mathbf{R}^{m}\right)$, 目的関数空間におけ る正象限を $\mathbf{R}_{+}^{m}$ で表すとき, $\left(E+\mathbf{R}_{+}^{m}\right)$ が凸になる場合, こ の効率フロンティアは凸であるという.
}

デルをすべて含むもので, 多入力-多出力の生産システム における意思決定体 (DMU) の相対的効率性を次のよう に測定する. 入力 $x_{i o}(i=1, \cdots, m)$, 出力 $y_{k o}(k=1, \cdots, n)$ をもつ DMU $o(o=1, \cdots, p)$ の効率性を次の線形計画問題 を解くことによって求める.

(GDEA)

$$
\begin{array}{cl}
\max _{\Delta, \mu, \nu} & \Delta \\
\text { s.t. } & \Delta \leq \tilde{d}_{j}+\alpha\left(\sum_{k=1}^{n} \mu_{k}\left(y_{k o}-y_{k j}\right)+\right. \\
& \left.\sum_{i=1}^{m} \nu_{i}\left(-x_{i o}+x_{i j}\right)\right), j=1, \cdots, p, \\
& \sum_{k=1}^{n} \mu_{k}+\sum_{i=1}^{m} \nu_{i}=1, \\
& \mu_{k}, \nu_{i} \geq \varepsilon, k=1, \cdots, n ; i=1, \cdots, m \\
\text { たたし, } \tilde{d}_{j}:=\max _{\substack{k=1, \cdots, n \\
i=1, \cdots, m}}\left\{\nu_{k}\left(y_{k o}-y_{k j}\right), \mu_{i}\left(-x_{i o}+x_{i j}\right)\right\} \\
\text { とおく. } \alpha \text { は正の定数とし, } \varepsilon \text { は小さい正数とする. }
\end{array}
$$

与えられた $\alpha$ に対する問題 (GDEA) を解いたとき, 求 められた最適值 $\Delta^{*}$ が, $\mathrm{DMU}_{o}$ の $\alpha$-効率値になる。こ のとき, 最適值 $\Delta^{*}$ が 0 ならば, DMUo は $\alpha$-効率的で あるという [14]. GDEA における $\alpha$-効率性は，十分大 きい $\alpha$ に対しては CCR 効率性と, 十分小さい $\alpha$ に対し ては FDH 効率性と等しくなることが知られている [14].

2. で述べたランキング法および DEA による方法の問 題点を改善するために, GDEA を用いた方法を提案す る.まず，制約式のある場合には，ペナルティ関数を用 いて, 目的関数 $f_{i}(i=1, \cdots, m)$ に対する拡大目的関数を 次のように定義する.

$$
\begin{gathered}
F_{i}(\boldsymbol{x})=f_{i}(\boldsymbol{x})+\sum_{j=1}^{l} p_{j} \times\left[P\left(g_{j}(\boldsymbol{x})\right)\right]^{a} \\
\text { ただし, } \quad p_{j}=\text { ペナルティ係数, } \\
\\
a=\text { ペナルティ指数, } \\
\\
P(y)=\max \{y, 0\}
\end{gathered}
$$

このとき, 与えられた問題は各々の目的関数に対する 拡大目的関数，(1) 式を最小化する問題になる.ここで, GDEA による各個体の効率度を測るためには，個体群を GDEA での評価されるDMUとする。また，GDEA は できる限り入力を小さく, 出力を大きくすることを目的 とするため, ある個体 $\boldsymbol{x}^{o}(o=1, \cdots, p)$ に対する拡大目 的関数值 $F_{i}\left(\boldsymbol{x}^{o}\right)$ を入力データと見なし, 出力データを 1 とする.このとき, 問題 (GDEA) は次のような問題に なり, ある個体 $\boldsymbol{x}^{\circ}(i=1, \cdots, p)$ の効率度は, 問題 $(\mathrm{P})$ を 解いたときの最適な $\Delta$ の值になる。この効率度をそのま ま, 適応度として選択が行われる。 
(P)

$$
\begin{array}{ll}
\max _{\Delta, \nu} & \Delta \\
\text { s.t. } & \Delta \leq \tilde{d}_{j}-\alpha \sum_{i=1}^{m} \nu_{i}\left(F_{i}\left(\boldsymbol{x}^{o}\right)-F_{i}\left(\boldsymbol{x}^{j}\right)\right), \\
& j=1, \cdots, p, \\
& \sum_{i=1}^{m} \nu_{i}=1, \\
& \nu_{i} \geq \varepsilon, i=1, \cdots, m
\end{array}
$$

ただし,$\tilde{d}_{j}=\max _{i=1, \cdots, m}\left\{\nu_{i}\left(-F_{i}\left(\boldsymbol{x}^{o}\right)+F_{i}\left(\boldsymbol{x}^{j}\right)\right)\right\}$ であり, $\varepsilon$ は小さい正数である. また， $\alpha$ は世代数に対する単調 減少関数値とする.

Fig. 3 に示されるように, 優越集合は $\alpha$ の值が小さ くなるにつれ半空間から錐へ小さくなっていく.これが, 十分大きい $\alpha$ に対しては GDEA モデルが CCR モデル と一致し, 十分小さい $\alpha$ に対してはFDH モデルと一致 することの幾何学的意味である。このような性質をもつ GDEA による方法は, 最初の段階では十分大きい $\alpha$ を 与えることにより，DEAによる方法と同じになるため， 非パレート個体をより早く淘汰することができる。さら に，世代が進むにしたがい $\alpha$ を小さくすることにより， ランキング法と一致するため, 効率フロンティアの非凸 な部分を求めることができる. そこで, GDEAによる方 法はランキング法と DEA による方法をミックスしてそ れらをより一般化した方法であるといえる。

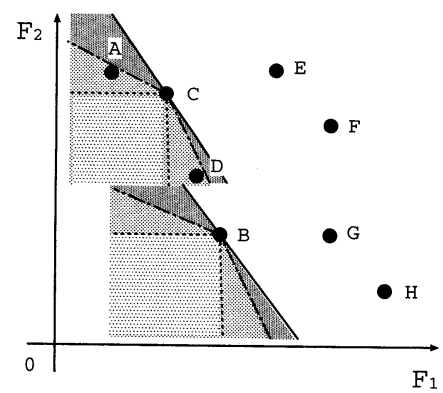

Fig. 3 Geometric interpretation of $\alpha$ in (P)

GDEA を用いた提案手法に扔いては, パラメー夕 $\alpha$ の 決め方が重要であるが, これは以下のようにして与える ことができる. 実際の問題では, 1 回の解析にかかる時 間は事前にほほ分かっているので, 1 世代の個体数と意 思決定までに与えられる時間が定められれば計算終了ま での世代数 $N$ は事前に与えることができる。このとき, $\alpha$ は例えば次のようにとればよい.

$$
\alpha(t):=\omega \cdot \exp (-\beta \cdot t), t=0,1, \cdots, N
$$

ここで, $\omega$ と $\beta$ は正の定数である. $\omega(=\alpha(0))$ は GDEA
において十分に大きい正数とされた数であるが, 通常は $10,10^{2}$ あるいは $10^{3}$ 程度の数にすればよいことが経験 上分かっている. $\beta$ は $\omega \cdot \exp (-\beta \cdot N)$ がほほ 0 になる值 として与えられる。

\section{4. 例題 -2 目的関数の最適化問題}

例題 1

$$
\begin{aligned}
\min _{\boldsymbol{x}} & \left(f_{1}(\boldsymbol{x}), f_{2}(\boldsymbol{x})\right)=\left(x_{1}, x_{2}\right) \\
\text { s.t. } & \left(x_{1}-2\right)^{2}+\left(x_{2}-2\right)^{2}-4 \leq 0, \\
& x_{1} \geq 0, x_{2} \geq 0
\end{aligned}
$$

例題 2[12]

$$
\begin{aligned}
\min _{\boldsymbol{x}} & \left(f_{1}(\boldsymbol{x}), f_{2}(\boldsymbol{x})\right)=\left(-2 x_{1}+x_{2},-x_{1}\right) \\
\text { s.t. } & \left(x_{1}-1\right)^{3}+x_{2} \leq 0 \\
& x_{1} \geq 0, x_{2} \geq 0
\end{aligned}
$$

例題 3

$$
\begin{aligned}
\min _{\boldsymbol{x}} & \left(f_{1}(\boldsymbol{x}), f_{2}(\boldsymbol{x})\right)=\left(x_{1}, x_{2}\right) \\
\text { s.t. } & x_{1}^{3}-3 x_{1}-x_{2} \leq 0 \\
& x_{1} \geq-1, x_{2} \leq 2
\end{aligned}
$$

以上に示した例題は, 効率フロンティアが例題 1 では 凸, 例題 2,3 では非凸になる 2 目的最適化問題である. これらの例題に対して, 本論文で提案した手法の有効性 を示すために, ランキング法 [5], 玉置ほかの方法 [12], DEA による方法 [1] を用いて比較する. 実際の計算手順 では, SGA(Simple Genetic Algorithms) が使われるが, そのパラメータは下に示す通りである. また, 次世代に 何を残すか, あるいは親としてどれを選ぶのかも重要で ある. その戦略としては, パレート保存戦略 [12], パレー ト・トーナメント戦略 [7], エリート保存戦略 [6] などが 提案されている.ここでは, 選択法としてはエリート保 存戦略 [6]を組み込む.

計算終了までの世代数 :

15 (例題 1), 20(例題 2), 30 (例題 3)

個体群のサイズ : 80

1 設計変数あたりの記号長 : 10 ビット

記号列から設計変数值への変換: 2 進記号列を

10 進数 $n_{i}$ に変換し, あらかじめ与えられ

た上限值 $x_{i}^{U}$ と下限値 $x_{i}^{L}$ を用いて,

$$
x_{i}=\frac{n_{i}}{2^{10}-1}\left(x_{i}^{U}-x_{i}^{L}\right)+x_{i}^{L}
$$

のように設計変数値へ変換する.

交叉確率 : 1 , 交叉点の数 : 2

突然変異 : 個体内の各ビットに対して確率 0.05

で反転させる。

$\alpha$ の設定 :

$10 \times \exp (-0.4 \times$ 世代) (例題 1$)$ 


$$
\begin{aligned}
& 10 \times \exp (-0.3 \times \text { 世代 })(\text { 例題 } 2) \\
& 10 \times \exp (-0.2 \times \text { 世代) }(\text { 例題 } 3) \\
& \varepsilon=10^{-6}
\end{aligned}
$$

Figs. 4-7 に各方法による計算の結果を示す. 横軸が $f_{1}$, 縦軸が $f_{2}$ を表す. 各図に, 四つの方法によって最終 世代まで求められたパレート個体を目的空間上に示す. その中で全世代を通じてのパレート個体を・で表し，あ る世代ではパレート個体であるが, 全世代を通じてはパ レート個体ではないものを。で表す.

(1) ランキング法

得られたパレート個体の数は比較的多いが，その 中には最終的なパレート個体にならないものが少 なからず存在する．また，Fig. 4 に見られるよう に滑らかな効率フロンティアを得にくい.

(2) 玉置ほかの方法

得られたパレート個体の数も多く, 効率フロンティ アもランキング法よりも滑らかである. しかしな がら, Fig. 5 からわかるように, 途中の世代のパ レート個体の中で, 最終的なパレート個体になら ない個体が多く存在する.

(3) DEA による方法

Fig. 6 の (a)に示されるように得られたパレート 個体の数は少ないが, 効率フロンティアは滑らか である。しかし，Fig. 6 における非凸な (b) と (c) ではくほんだ部分が得られない，そのため，DEA による方法は凸な効率フロンティアを求める問題 にしか適用できないという短所がある。

(4) GDEA による方法

本論文で提案した方法による結果は, Fig. 7 から もわかるように，凸な効率フロンティア，非凸な 効率フロンティアのいずれにおいてもパレート個 体の数は多く, 得られた効率フロンティアも滑ら かである.さらに，各世代において求められたパ レート個体の多くが最終的なパレート個体になる ことがわかる.

とくに，ランキング法および玉置ほかの方法において 途中の世代のパレート個体の中で, 最終的なパレート解 にならない個体が多く存在することには注目する必要が ある. 実際の問題において度々少ない世代数で打ち切るこ とがあるが, このようなとき, 少ない世代数で打ち切って も得られたパレート個体が正しい効率フロンティアにで きるかぎり近いことが望まれる.この点, DEA や GDEA による方法は良好な結果を与えていることが上の例題か らわかる。

\section{5. おわりに}

本論文では, 多目的最適化問題における効率フロンティ アを直接的に求めることを目指して, GDEA と遺伝アル ゴリズムを用いた多目的最適化手法を提案した．この方 法は, 従来の方法がもっていた問題点を改善し, かつ従 来の方法の長所を受け継いだ方法となっている．そのた め, 効率フロンティアをより早く, しかもより多くのパ レート個体を求めることができ,さらに，目的関数が非 凸な場合にも適用できるようになっている，反面，各世代 の個体に対し, GDEA の効率性を判定する線形計画問題 (P) を解くために時間がかかるという短所があるが, こ れは多くの工学設計問題においては解析 (構造解析, 熱解 析, 流体解析など) にかかる時間が圧倒的に大きいので, 問題にならない範囲といえる．本研究で提案した方法に おいて少ない世代数で真の効率フロンティアに対する良 い近似の効率フロンティアが得られるという点は, 解析 に時間がかかるような意思決定問題に対しとくに有効で あると考えられる。 


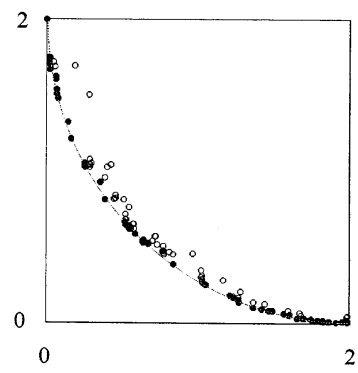

(a) Example 1

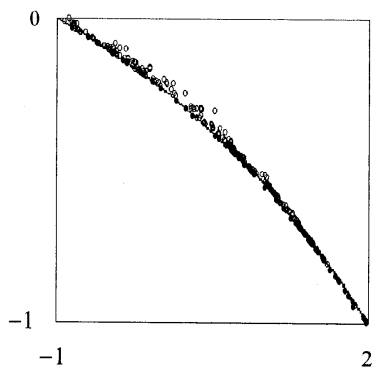

(b) Example 2

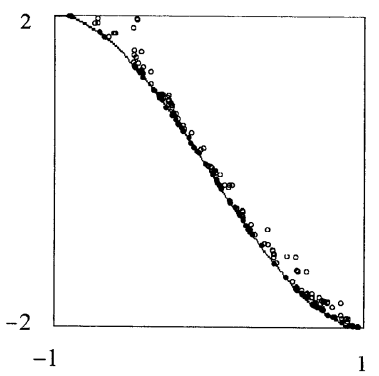

(c) Example 3

Fig. 4 Efficient frontiers generated by Ranking Method

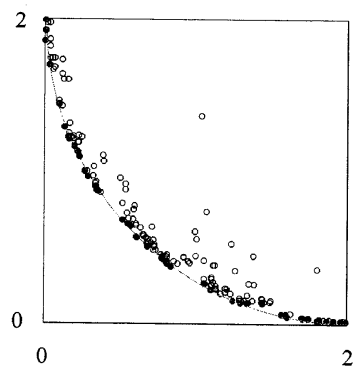

(a) Example 1

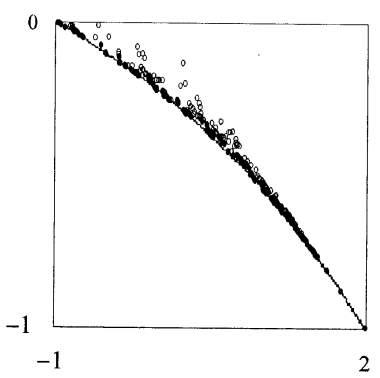

(b) Example 2

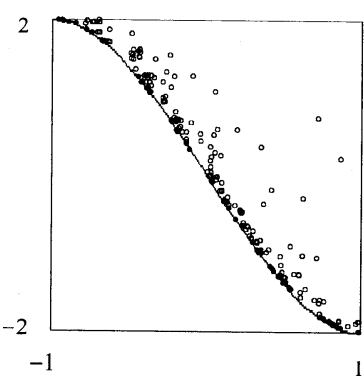

(c) Example 3

Fig. 5 Efficient frontiers generated by Tamaki et al.'s Method

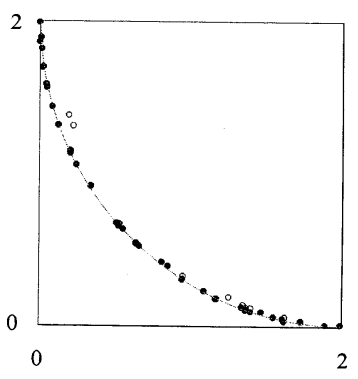

(a) Example 1

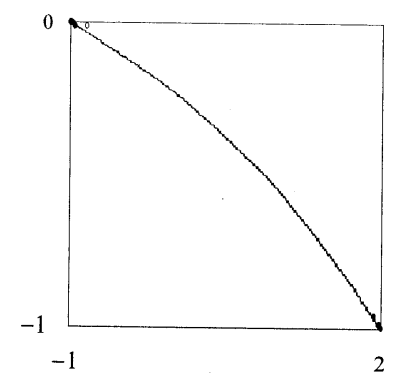

(b) Example 2

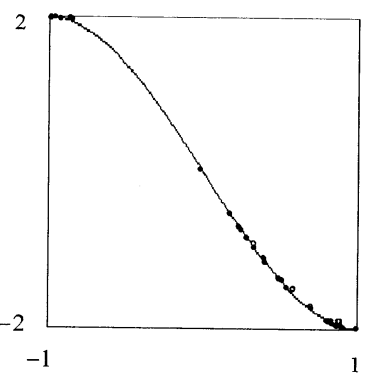

(c) Example 3

Fig. 6 Efficient frontiers generated by DEA Method

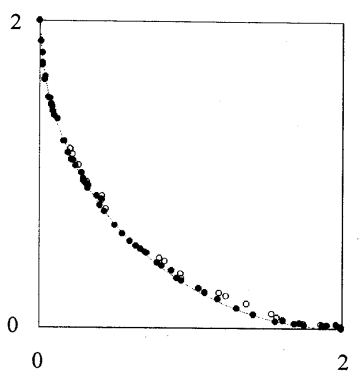

(a) Example 1

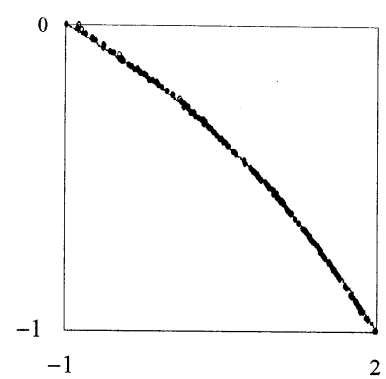

(b) Example 2

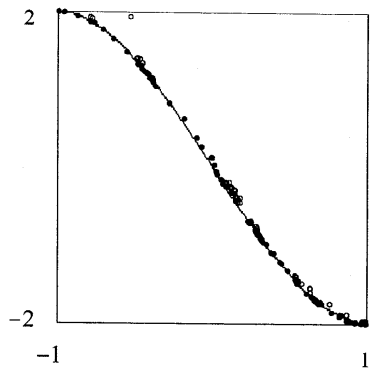

(c) Example 3

Fig. 7 Efficient frontiers generated by GDEA Method 


\section{参 考文 献}

[1] M. Arakawa, H. Nakayama, I. Hagiwara and H. Yamakawa: Multiobjective optimization using adaptive range genetic algorithms with data envelopment analysis; A Collection of Technical papers on 7th Symposium on Multidisciplinary Analysis and $O p$ timization (TP98-4970), AIAA, Vol. 3, pp. 20742082 (1998)

[2] R.D. Banker, A. Charnes and W.W. Cooper: Some models for estimating technical and scale inefficiencies in data envelopment analysis; Management Science, Vol. 30, pp. 1078-1092 (1984)

[3] A. Charnes, W.W. Cooper and E. Rhodes: Measuring the efficiency of decision making units; European Journal of Operational Research, Vol.2, pp. 429-444 (1978)

[4] D. Deprins, L. Simar and H. Tulkens: Measuring labor-efficiency in post offices; The Performance of Public Enterprises:Concepts and Measurements (edited by M. Marchand, P. Pestieu and H. Tulkens), North Holland, Amsterdam, pp. 247-263 (1984)

[5] C.M. Fonseca and P.J. Fleming: Genetic algorithms for multi-objective optimization:Formulation, discussion and generalization; Proc. of the Fifth International Conference on Genetic Algorithms, pp. 416426 (1993)

[6] D.E. Goldberg: Genetic Algorithms in Search, Optimization and Machine Learning, Addison-Wesley, Massachusetts (1989)

[7] J. Horn, N. Nafpliotis and D.E. Goldberg: A niched Pareto genetic algorithm for multiobjective optimization; Proc. of ICEC'94, pp. 82-87 (1994)

[8] T.C. Koopmans: Analysis of production as an efficient combination of activities; Analysis of Production and Allocation (T.C. Koopmans), John Wiley, pp. 33-97 (1951)

[9] 森, 薮本, 喜多, 西川: 熱力学的遺伝アルゴリズムによる多 目的最適化; システム制御情報学会論文誌, Vol. 11 , No. 3 , pp. 103-111 (1998)

[10] 中山, 谷野: 多目的計画法の理論と応用, 計測自動制御学 会, pp. 42-50 (1994)

[11] J.D. Schaffer: Multiple objective optimization with vector evaluated genetic algorithms; Proceeding of the First International Conference on Genetic Algorithms, pp. 93-100 (1985)

[12] 玉置, 森, 荒木: 遺伝アルゴリズムを用いたパレート最適解 集合の生成法; 計測自動制御学会論文集, Vol. 31 , No. 8, pp. 1185-1192 (1995)

[13] H. Tulkens: On FDH efficiency: Some methodological issues and applications to retail banking, courts and urban transit; Journal of Productivity Analysis, Vol. 4, pp. 183-210 (1993)

[14] 尹, 中山, 谷野: 包絡分析法 (DEA) の一般化; 計測自動制 御学会論文集, Vol. 35 , No. 8, pp. 1813-1818 (1999) 